\title{
CAMBIOS EN EL CAUCE Y EL LLANO DE INUNDACIÓN DEL RÍO EBRO (ARAGÓN) EN LOS ÚLTIMOS 80 AÑOS
}

\author{
Alfredo Ollero Ojeda, Daniel Ballarín Ferrer y Daniel Mora Mur \\ Dpto. de Geografía y Ordenación del Territorio - Facultad de Filosofía y Letras, \\ Universidad de Zaragoza. Pedro Cerbuna, 12. 50009 Zaragoza \\ aollero@unizar.es
}

\begin{abstract}
Resumen: El curso medio del río Ebro ha asistido en los últimos 80 años a notables cambios, tanto en el trazado de su cauce menor como en los usos del suelo del llano de inundación. Se han analizado los cambios observados entre las fotografías aéreas de 1927, 1957 y 1998. Han sido frecuentes la ampliación de sinuosidades y la migración y corta de meandros. Ha habido un progresivo y considerable descenso de la superficie ocupada por el cauce inundado y las barras de grava sin colonización vegetal, reduciéndose notablemente la anchura del corredor ribereño en beneficio de usos humanos. La ralentización y casi eliminación de la dinámica del cauce del Ebro de meandros libres constituye una destacable pérdida de patrimonio natural.
\end{abstract}

Palabras clave: dinámica fluvial, corredor ribereño, llano de inundación, río Ebro, Aragón.

\begin{abstract}
The middle Ebro River during the last 80 years has attended to notable changes in channel morphology and area of bars, riparian vegetation and floodplain uses. Adjustments are observed among aerial photographs of 1927, 1957 and 1998. It has been frequent sinuosity growth, migrations and meander cut off. There has been a progressive and considerable decrease in flood channel area and gravel bars without vegetal colonization as a result the riparian corridor width has been reduced for increase human uses. The slowing down and nearly elimination to the channel free meanders dynamic in Ebro River represent an outstanding natural patrimony loss.
\end{abstract}

Key words: channel changes, riparian corridor, floodplain, Ebro River, Aragón.

\footnotetext{
* Recibido: 5-10-2006. Aceptado: 15-12-2006.
} 


\section{Introducción y antecedentes}

Los cursos fluviales son sistemas en equilibrio dinámico (Chorley y Kennedy, 1971), en ajuste permanente en el espacio y en el tiempo ante las fluctuaciones de caudal líquido y sólido, lo cual se traduce en movilidad lateral y vertical (Werritty, 1997). Esta movilidad es un mecanismo de regulación y es también el motor de una dinámica ecológica intensa que garantiza la riqueza y diversidad de estos sistemas naturales (Malavoi et al., 1998). Diversas actividades humanas tienen alta capacidad de modificación de esta dinámica fluvial.

El curso medio del río Ebro ha asistido en los últimos 80 años a notables cambios, tanto en el trazado de su cauce menor como, principalmente, en los usos del suelo del llano de inundación y en la superficie ocupada por depósitos de gravas y vegetación de ribera. Estas modificaciones han sido estudiadas y descritas cualitativamente en trabajos anteriores (Ollero y Pellicer, 1991; Ollero, 1991, 1992, 1995, Ollero et al., 2004), pero faltaba una evaluación cuantitativa, que se ha podido llevar a cabo mediante una herramienta SIG.

Los cambios observados responden a un proceso de antropización al que han asistido la mayor parte de los ríos del planeta, y cuyas consecuencias hidrológicas, geomorfológicas y ecológicas han sido evaluadas en otros sistemas fluviales europeos, como por ejemplo en los trabajos de Décamps et al. (1989); Roux et al. (1989), Bravard (1991), Rumsby y Macklin (1994), Lajczak, A. (1995), Marston et al. (1995), Macklin y Lewin (1997), Conesa (1999), Surian (1999), Brandt (2000), Winterbottom (2000), García Martínez y Baena (2001), Liébault y Piégay (2002), Rinaldi (2003), Surian y Rinaldi (2003), Uribelarrea et al. (2003), Keesstra et al. (2005), etc. También se ha abordado esta temática en los propios afluentes del Ebro: García Ruiz et al. (2001), Beguería et al. (2003), Batalla (2003), Batalla et al. (2004), Acín (2004), Granado (2004), Frutos et al. (2004), Ollero (dir., 2005). Igualmente hay abundante bibliografía en sistemas fluviales de otros continentes: Schumm (1968), Bray y Kellerhals (1979), Goswami et al. (1999), Rutherfurd (2000), Apan et al. (2002), Gergel et al. (2002), etc. En la mayor parte de los casos estudiados se ha asistido a procesos de transformación de cauces trenzados en sinuosos, con clara simplificación del canal, a problemas por incisión lineal, a procesos de invasión humana del corredor ribereño y a reducciones significativas de la movilidad de los cauces en las últimas décadas.

Por lo que respecta a los tipos de cambio o de ajuste geomorfológico que se pueden registrar en ríos aluviales de llanura, existen diversas clasificaciones, como las de Brice (1981), Brookes (1987), Downs (1992), Hooke (1997) o Thorne (1998). Con base en ellas se estableció una tipología adaptada al curso bajo del Gállego (Ollero, 
dir., 2005), la cual se ha empleado como base para clasificar los cambios geomorfológicos observados en el cauce del Ebro.

\section{2. Área de estudio}

Entre Logroño y La Zaida, en el centro de la Depresión del Ebro, a lo largo de $346,5 \mathrm{~km}$ de cauce, el Ebro describe un curso de meandros libres que divagan sobre una extensa llanura de inundación, cuya anchura media es de $3,21 \mathrm{~km}$, alcanzando un máximo de $6 \mathrm{~km}$. Es el curso fluvial de estas características más largo de la Península Ibérica. El índice de sinuosidad medio, de acuerdo con el criterio de Brice (1964), es decir, dividiendo la longitud del talweg entre la longitud del eje de la banda de meandros, es de 1,505, y la pendiente media del cauce de tan sólo $0,00067 \mathrm{~m} / \mathrm{m}$ (Ollero, 1992).

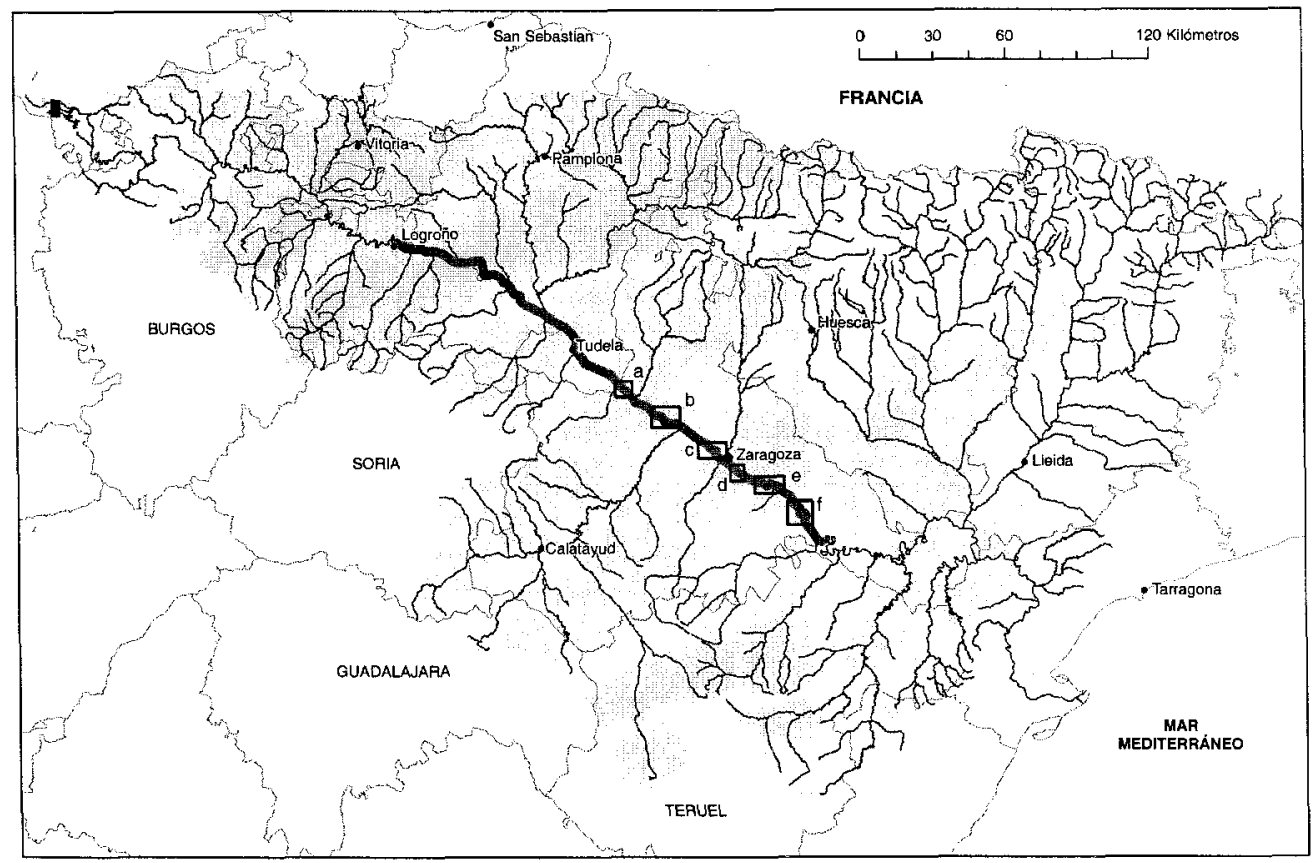

Figura 1. El Ebro de meandros libres (trazo grueso) en el contexto de la cuenca del Ebro. Se localizan los seis sectores dinámicos en los que se han realizado evaluaciones de detalle: a) Novillas; b) Luceni-Cabañas; c) Sobradiel-Juslibol; d) R.N.Galachos; e) Villafranca-Osera; f) Pina de Ebro.

Elaboración propia sobre base cartográfica de la Confederación Hidrográfica del Ebro. 
La mitad inferior del Ebro de meandros libres se integra en la Comunidad Autónoma de Aragón, ámbito de estudio en el que se centra exclusivamente el presente trabajo. En este tramo aragonés el índice de sinuosidad es más alto que la media $(1,608)$, la pendiente del cauce más baja $(0,00053)$ y la anchura media del llano de inundación asciende a $3,77 \mathrm{~km}$. La anchura media del cinturón de meandros es de $955 \mathrm{~m}$ y la del cauce menor en bankfull de $147 \mathrm{~m}$ (Ollero et al., 2004).

Hay importantes diferencias entre márgenes. Las convexas o lóbulos de meandro están conformadas por materiales sedimentarios mayoritariamente gruesos (pointbars) y fácilmente inundables, por lo que no han sido puestas en cultivo en su totalidad y conservan masas de vegetación de ribera o sotos. Las cóncavas, generalmente más elevadas sobre la corriente ( 2 a $3 \mathrm{~m}$ ) y formadas por materiales finos depositados por decantación en los procesos de crecida, carecen de formaciones vegetales, se encuentran cultivadas hasta la misma orilla y en su práctica totalidad defendidas para evitar su erosión.

La llanura de inundación, conformada por depósitos de desbordamiento originados por decantación y acreción vertical de materiales finos, muestra muy abundantes huellas de antiguos cauces abandonados de planta semicircular (como corresponde al trazado meandriforme), pruebas evidentes de una dinámica fluvial muy activa en el pasado.

Con un caudal medio de $216,5 \mathrm{~m}^{3} / \mathrm{s}$ en Zaragoza (serie 1943-2002), el régimen hidrológico del Ebro medio es pluvio-nival con máximo en febrero y estiaje estival. La influencia pluvial oceánica produce los notables caudales invernales, además de la mayor frecuencia de crecidas en dicha estación. A lo largo del curso fluvial se constata una pérdida progresiva de caudal específico. Las crecidas son predominantemente invernales y con una elevada frecuencia de casi dos por año. Entre las avenidas extraordinarias del siglo XX destaca la de diciembre de $1960\left(4.950 \mathrm{~m}^{3} / \mathrm{s}\right.$ en el aforo de Castejón). Se producen importantes desbordamientos por la falta de encajamiento del cauce, lo cual lamina la crecida aplanando el hidrograma aguas abajo (Ollero, 1992).

Los bosques de ribera del Ebro constituyen un conjunto de formaciones vegetales que incluyen comunidades palustres y acuáticas, carrizales, pioneras, formaciones herbáceas de juncal y prado, formaciones arbustivas y de orla (tamarizales, que avanzan, y saucedas, en retroceso) y formaciones maduras de porte arbóreo con la trilogía Populus nigra, Populus alba, Salix alba. Aún quedan algunas olmedas externas, junto a formaciones derivadas de la degradación del soto, principalmente orlas espinosas y comunidades nitrófilas. Cuentan con un elevado valor paisajístico y bioclimático en mitad del ambiente semiárido de la Depresión. En el tramo aragonés del Ebro de meandros libres las masas de vegetación de ribera suman una extensión de unas 1.775 hectáreas. Perviven en los enclaves más dinámicos, especialmente en ori- 
llas convexas, islas en el centro del cauce y galachos (meandros abandonados), cubriendo únicamente el 4,5\% de la superficie de la llanura de inundación, y limitándose al $40 \%$ de la extensión que ocupaban en 1950 (Ollero, 1992). Lejos de encontrar un pasillo vegetal ribereño continuo acompañando al cauce a modo de bosque-galería, los sotos actuales son enclaves desconectados entre sí.

\section{Metodología}

Las imágenes cartográficas antiguas habrian permitido un estudio retrospectivo hasta el siglo XIX, pero se ha comprobado que su fiabilidad era escasa. Por ello, para el presente análisis se ha optado por utilizar exclusivamente fotografías aéreas. Se han consultado los vuelos de 1927, 1946, 1957, 1981-84, 1982, 1991, 1998 y 2000. De todos ellos se han seleccionado para analizar los cambios el más antiguo, de 1927, el llamado "vuelo americano" de 1957 y el del "SIG oleícola" de 1998, tanto por motivos técnicos como por ser perfectamente representativos de tres fases muy claras en la historia reciente del río Ebro. Cabe destacar por su calidad y gran interés documental las fotografías del vuelo pionero de 1927, ya que posibilitan el reconocimiento preciso del cauce del Ebro medio con anterioridad a las grandes infraestructuras de regulación de la cuenca. Fue realizado por CETFA por encargo de la recién creada Confederación Sindical Hidrográfica del Ebro, a escala aproximada 1:9.000, siendo la mayor parte de las fotografías de febrero de 1927 (Ollero y Pellicer, 1989). En el desarrollo futuro de la investigación se espera incorporar al análisis algún otro vuelo, como el de 1982.

Las fotografias de 1927 y 1957 han sido georreferenciadas sobre base topográfica y con la ayuda de las imágenes de 1998, que se encuentran ya georreferenciadas. A cada una de las imágenes se le ha asignado la proyección de un sistema de coordenadas European Datum 1950 UTM Zona 30N porque abarca toda el área de estudio. El correspondiente proceso de georreferenciación ha sido realizado con mucho detalle para poder analizar los cambios en los usos del suelo de forma precisa mediante las herramientas del SIG. En la figura 2 se presentan superpuestos los trazados generales del cauce menor del Ebro entre Novillas y La Zaida a partir de las tres fotografías aéreas seleccionadas.

Para un análisis de detalle del llano de inundación se han establecido 6 categorías, que son las que se han cartografiado en cada uno de los tres momentos de estudio. Dichas categorías son: río Ebro (cauce inundado), barras de grava, vegetación de ribera, praderas y primicolonizadoras, zonas urbanas, otros usos. 


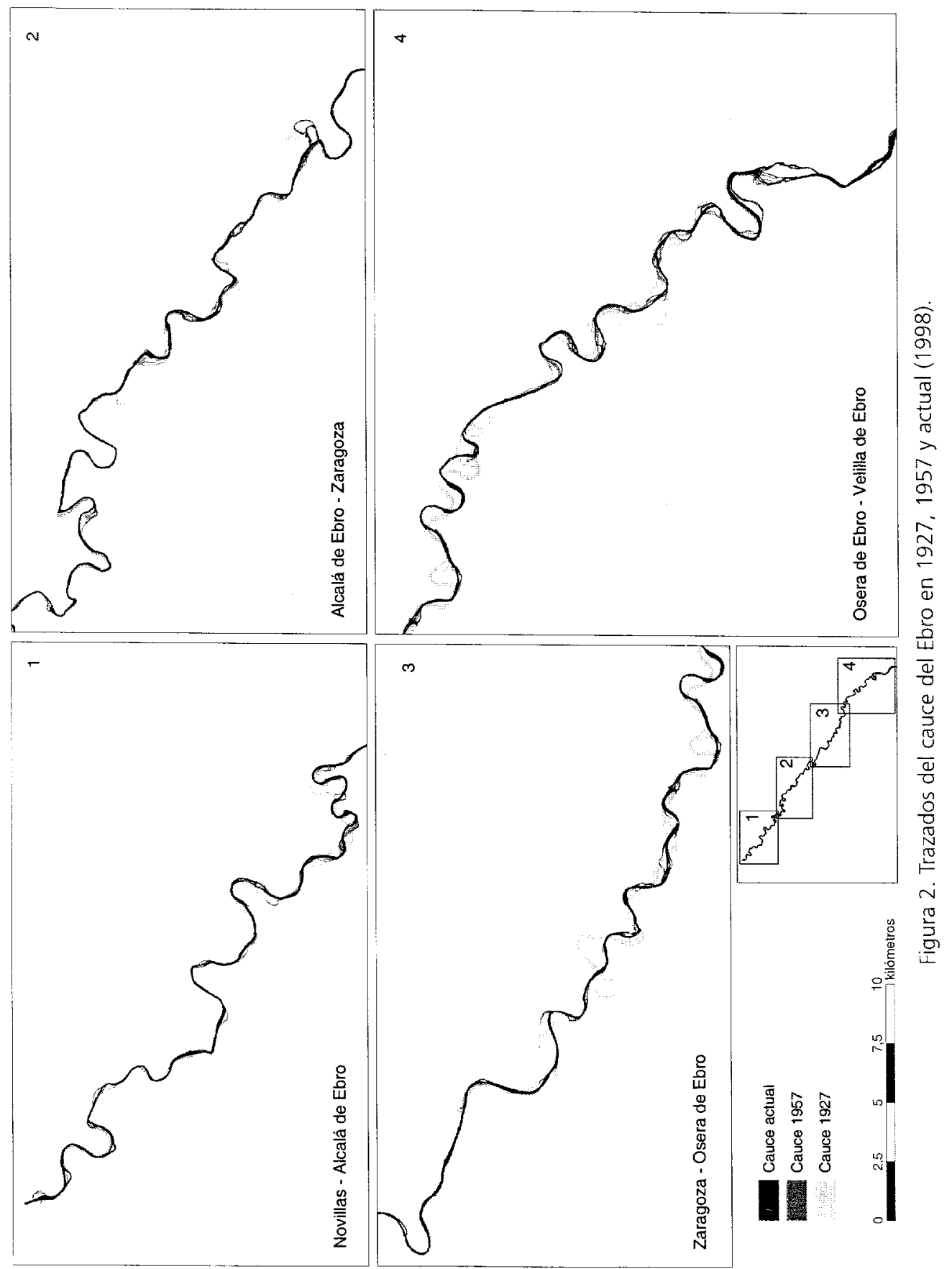


La mayor resolución espacial de los fotogramas de 1998 y 1927 hace posible la discriminación de un mayor número de categorías. Sin embargo, para el análisis multitemporal de cambios en los usos del suelo, se han simplificado los tres años en las seis categorias citadas con anterioridad.

Se ha llevado a cabo una valoración cuantitativa de superficies modificadas por cambios en el trazado del cauce, en un total de 83 enclaves con variaciones significativas. Se ha calculado tanto la superficie modificada en hectáreas como la intensidad del cambio. Este segundo parámetro, en metros lineales, se ha establecido midiendo los desplazamientos de los vértices de meandro o distancias de movimiento máximo en otros tipos de cambios.

Igualmente se han cuantificado los cambios superficiales en el llano de inundación de las 6 categorías establecidas en otras tantas zonas preseleccionadas por ser las de mayor dinámica registrada en el cauce: Novillas, Luceni-Cabañas, SobradielJuslibol, Reserva Natural de los Galachos, Villafranca-Osera y Pina de Ebro.

\section{Resultados y discusión}

\subsection{Tipología y dimensiones de los cambios registrados}

Se han encontrado cambios relevantes entre 1927 y 1998 en 83 enclaves. Los cambios han sido clasificados por tipos (tabla 1).

Los tipos de cambio registrados son, como corresponde a un curso de meandros libres, fundamentalmente tres: ampliación, migración y corta. A continuación se ordenan en función del número de casos estos tres tipos básicos junto con otros encontrados:

- Ampliación de sinuosidad, por incremento de la amplitud de onda del meandro (erosión en margen cóncava, sedimentación en margen convexa), sin migración. Ha habido 38 casos.

- Migración de meandro, progresión de la curva aguas abajo por erosión aguas abajo del vértice y progresión de point-bar. Se han registrado 32 casos.

- Ampliación + migración, dinámica de meandro más activa que combina entre las dos fechas de fotografías aéreas los dos procesos anteriores. Se han dado 21 casos.

- Acortamiento, reducción de tamaño por corta de canal de crecida (cbute cut-off) que ha afectado a poca superficie del lóbulo. Ha habido 17 casos.

- Corta de cuello de meandro (neck cut-off). Ha habido 7 casos.

- Corta + ampliación. Se han dado 3 casos. 
- Trenzamiento o subdivisión en brazos de un cauce anteriormente único. Ha habido solo dos casos en el Ebro.

- Migración + acortamiento (1 caso).

- Migración + trenzamiento (1 caso).

- Pequeña avulsión, cambio de trazado radical, en este único caso de muy pequeñas dimensiones, pasando la margen cóncava a convexa y viceversa.

- Un retroceso en confluencia (Huecha).

Por lo que respecta a las dimensiones del cambio, queda muy claro que se registraron más cambios y en general de mayores dimensiones entre 1927 y 1957 que posteriormente. La superficie movilizada fue de casi 2.000 hectáreas entre 1927 y 1957, mientras entre 1957 y 1998 ha sido de solo unas 400 hectáreas, a pesar de que el periodo de tiempo en este segundo intervalo es mayor.

El sumatorio de la intensidad de cambio en los 83 enclaves activos arroja un való de $30.332 \mathrm{~m}$ entre 1927 y 1957 frente a $9.446 \mathrm{~m}$ entre 1957 y 1998. Ello supone que la intensidad media de cambio fue de 12,2 metros por enclave y año en el periodo 1927-57, mientras en el periodo $1957-98$ se redujo a $2,8 \mathrm{~m}$ por enclave y año.

\subsection{Sectores de mayor cambio}

Se ha seleccionado un conjunto de sectores con notables cambios en el periodo 1927-1998 para analizar también los cambios en las superficies ribereñas y de usos del suelo. Los resultados se recogen en las tablas 2 y 3 y se representan en los mapas de las figuras 4 a 9 .

Los aspectos más relevantes de la evolución analizada son los siguientes:

- Ha descendido considerablemente la superficie ocupada por el cauce inundado y las barras de grava sin colonización vegetal, como efecto fundamental de los embalses, que han propiciado la aproximación de la vegetación hasta la lámina de agua.

- La vegetación de ribera descendió en superficie entre 1927 y 1957 debido a la ocupación de terrenos ribereños conforme se iba estabilizando el cauce. El descenso es considerable en primicolonizadoras, lo cual es un indicador básico de estabilización del sistema y pérdida de trenzamiento. Sin embargo, la vegetación de ribera madura aumentó de 1927 a 1957, alcanzando los sotos del Ebro la mayor extensión. Los sotos ocuparon el terreno de las primicolonizadoras, situándose más cerca del cauce, mientras los cultivos avanzaron sobre los viejos sotos y parte de las primicolonizadoras también.

- Entre 1957 y 1998 se ha reducido la anchura de la vegetación de ribera y del corredor ribereño. El avance de los usos agrarios y urbanos ha seguido siendo efectivo, como se observa en el incremento de la superficie de áreas humanas (Tabla 3). 


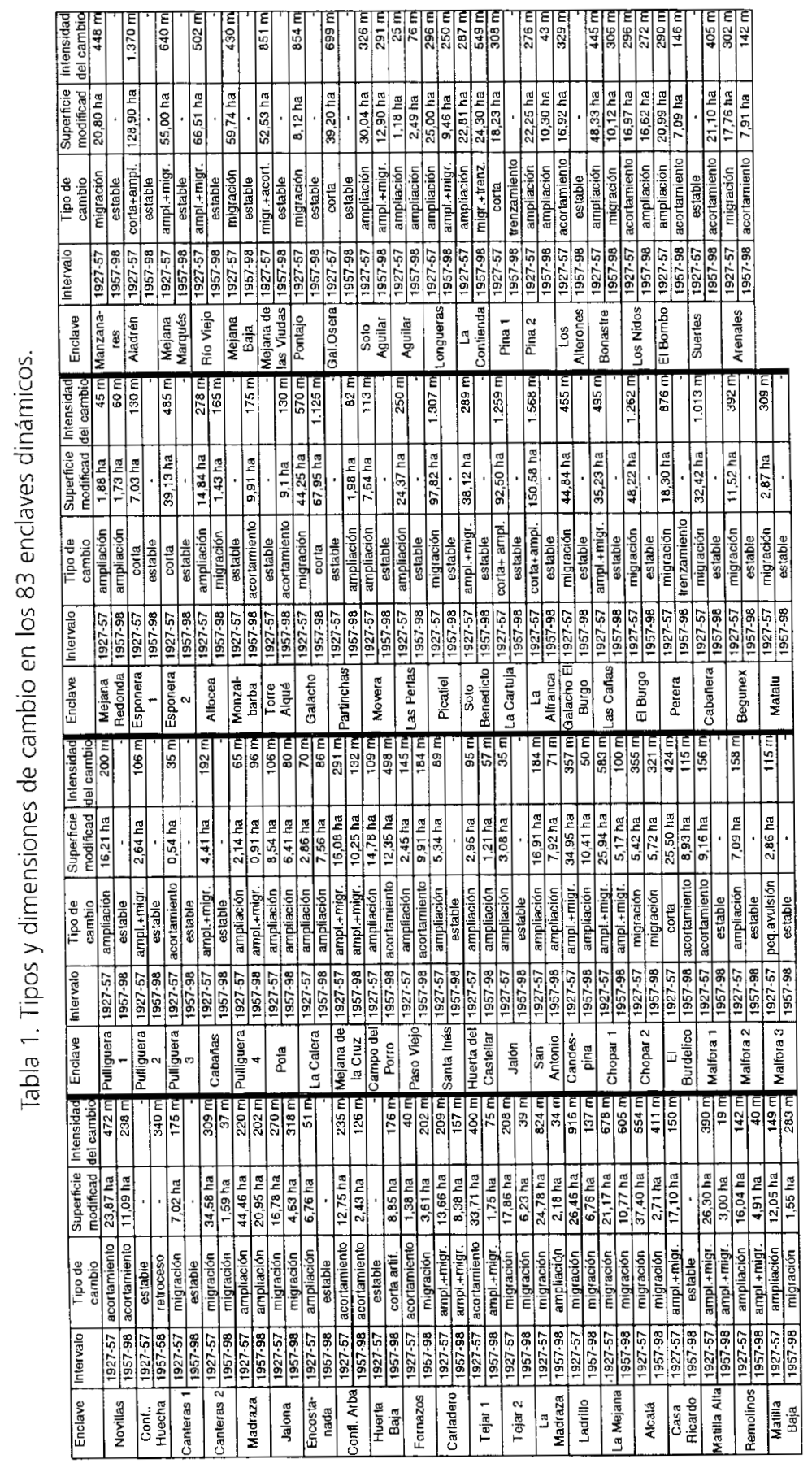


Tabla 2. Evolución por tipos de superficie (en hectáreas) entre 1927, 1957 y 1998 en los espacios más dinámicos

\begin{tabular}{|c|c|c|c|c|c|c|c|c|}
\hline & Año & $\begin{array}{l}\stackrel{9}{3} \\
\stackrel{3}{3} \\
\text { 吕 }\end{array}$ & 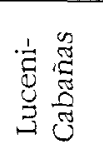 & 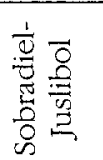 & 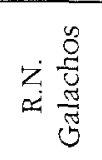 & 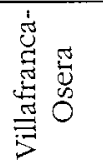 & $\underset{\tilde{B}}{\tilde{B}}$ & 正 \\
\hline Cauce inundado & $\begin{array}{l}1927 \\
1957 \\
1998\end{array}$ & $\begin{array}{l}36,2 \\
47,0 \\
34,1\end{array}$ & $\begin{array}{l}128,1 \\
188,2 \\
145,2\end{array}$ & $\begin{array}{l}146,8 \\
133,2 \\
121,2\end{array}$ & $\begin{array}{l}243,6 \\
220,4 \\
178,5\end{array}$ & $\begin{array}{l}205,4 \\
160,0 \\
148,6\end{array}$ & $\begin{array}{l}141,1 \\
133,2 \\
121,2\end{array}$ & $\begin{array}{l}901,2 \\
882,0 \\
748,8\end{array}$ \\
\hline Barras & $\begin{array}{l}1927 \\
1957 \\
1998\end{array}$ & $\begin{array}{r}48,4 \\
23,2 \\
8,0\end{array}$ & $\begin{array}{r}125,8 \\
78,2 \\
8,4\end{array}$ & $\begin{array}{r}145,5 \\
113,3 \\
26,0 \\
\end{array}$ & $\begin{array}{r}231,5 \\
82,8 \\
85,9\end{array}$ & $\begin{array}{r}146,2 \\
78,9 \\
55,0\end{array}$ & $\begin{array}{r}149,2 \\
113,3 \\
26,0\end{array}$ & $\begin{array}{l}846,6 \\
489,7 \\
209,3\end{array}$ \\
\hline Primicolonizadoras & $\begin{array}{l}1927 \\
1957 \\
1998\end{array}$ & $\begin{array}{l}38,6 \\
54,4 \\
24,4\end{array}$ & $\begin{array}{r}312,8 \\
202,5 \\
85,2 \\
\end{array}$ & $\begin{array}{l}352,2 \\
311,3 \\
109,8\end{array}$ & $\begin{array}{l}114,9 \\
355,0 \\
343,0\end{array}$ & $\begin{array}{l}558,0 \\
195,7 \\
157,5\end{array}$ & $\begin{array}{l}734,0 \\
311,3 \\
109,8\end{array}$ & $\begin{array}{r}2110,5 \\
1430,2 \\
829,7\end{array}$ \\
\hline $\begin{array}{l}\text { Vegetación de } \\
\text { ribera madura }\end{array}$ & $\begin{array}{l}1927 \\
1957 \\
1998\end{array}$ & $\begin{array}{l}11,3 \\
25,2 \\
34,4\end{array}$ & $\begin{array}{r}25,2 \\
47,2 \\
147,8\end{array}$ & $\begin{array}{l}38,5 \\
82,0 \\
77,6\end{array}$ & $\begin{array}{r}6,6 \\
173,3 \\
125,5\end{array}$ & $\begin{array}{r}0 \\
29,6 \\
64,1\end{array}$ & $\begin{array}{l}57,4 \\
82,0 \\
77,6\end{array}$ & $\begin{array}{l}139,0 \\
439,3 \\
527,0\end{array}$ \\
\hline Áreas & $\begin{array}{l}1927 \\
1957 \\
1998\end{array}$ & $\begin{array}{r}6,9 \\
6,7 \\
15,7\end{array}$ & $\begin{array}{l}11,4 \\
15,8 \\
47,5\end{array}$ & $\begin{array}{r}7,2 \\
26,4 \\
94,1\end{array}$ & $\begin{array}{r}32,3 \\
50,5 \\
196,9\end{array}$ & $\begin{array}{r}0 \\
7,5 \\
69,4\end{array}$ & $\begin{array}{l}17,5 \\
26,4 \\
94,1\end{array}$ & $\begin{array}{r}75,3 \\
133,3 \\
517,7\end{array}$ \\
\hline $\begin{array}{l}\text { Otros usos } \\
\text { (agrarios) }\end{array}$ & $\begin{array}{l}1927 \\
1957 \\
1998\end{array}$ & $\begin{array}{l}273,1 \\
257,9 \\
297,7\end{array}$ & $\begin{array}{l}2136,8 \\
2208,4 \\
2306,2\end{array}$ & $\begin{array}{l}1311,6 \\
2098,0 \\
2335,9\end{array}$ & $\begin{array}{l}2995,1 \\
3740,7 \\
3695,0\end{array}$ & $\begin{array}{l}1952,9 \\
2390,6 \\
2367,5\end{array}$ & $\begin{array}{l}1665,2 \\
2098,0 \\
2335,9\end{array}$ & $\begin{array}{l}10334,7 \\
12793,6 \\
13338,2\end{array}$ \\
\hline
\end{tabular}

Tabla 3. Evolución de superficies (hectáreas) totales del cauce, corredor ribereño y resto de la zona inundable entre 1927, 1957 y 1998 en el conjunto de espacios dinámicos

\begin{tabular}{|lccc|}
\hline & 1927 & 1957 & 1998 \\
\hline Cauce inundado + barras & 1747,8 & 1371,7 & 958,1 \\
Vegetación de ribera & 2249,5 & 1869,5 & 1356,7 \\
Áreas humanas & 10410,0 & 12926,9 & 13855,9 \\
\hline
\end{tabular}

- En suma, las áreas naturales constituían el 27,7\% de la llanura de inundación en 1927, el 20\% en 1957 y el 14,3\% en 1998. La superficie actual del corredor ribereño no llega al 58\% de la que había en 1927.

a) Novillas: el Ebro desarrolla en este sector meandros de amplio radio que han registrado importantes procesos de migración (figura 4). En la primera de las curvas se ha asistido a un progresivo acortamiento del lóbulo del meandro, con migración del vértice hacia aguas abajo. Esta dinámica ha implicado cambios en la ubicación de 


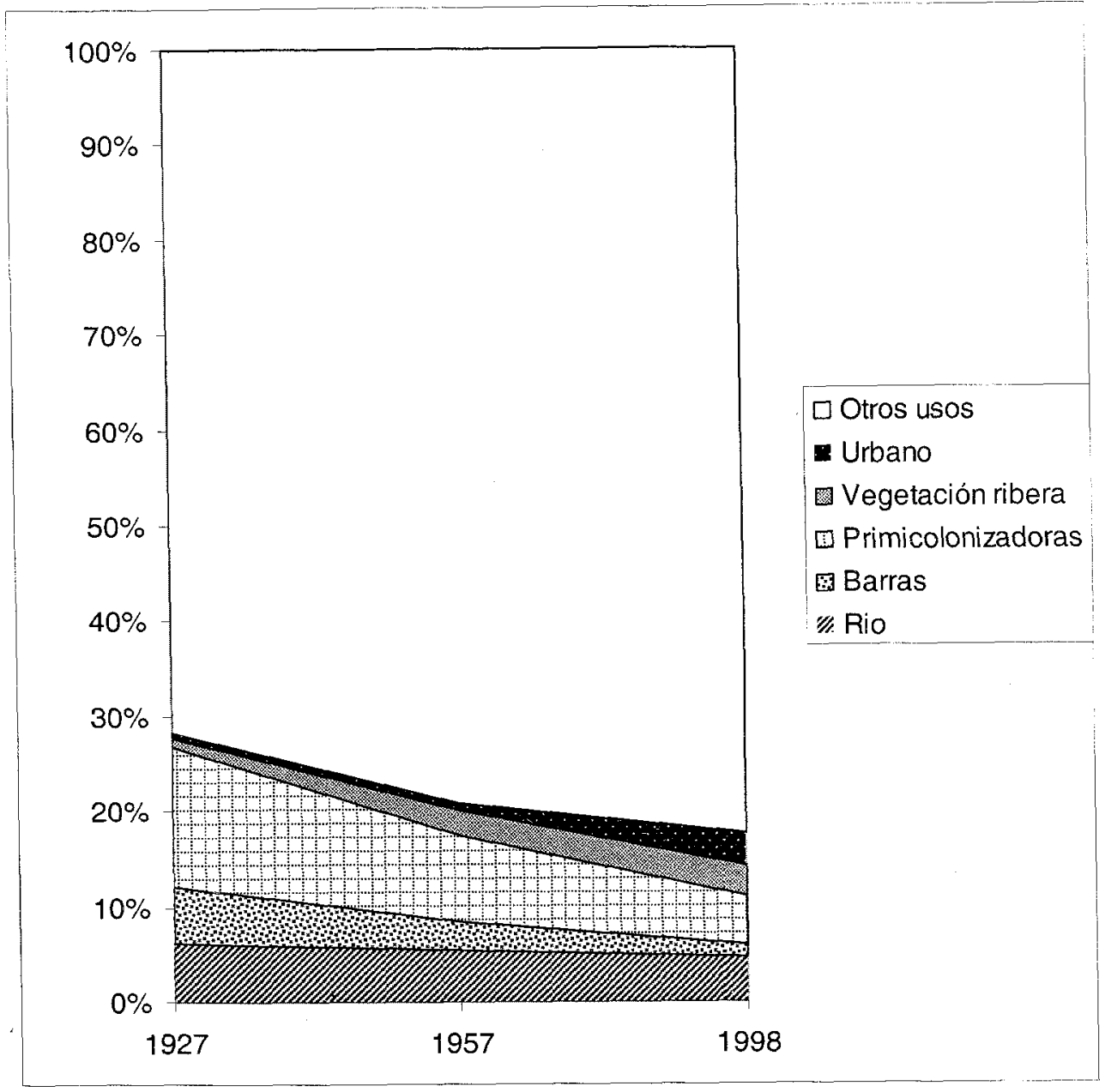

Figura 3. Porcentajes de superficie ocupada por cada uno de los tipos en 1927, 1957 y 1998. sumando los seis espacios dinámicos estudiados.

la confluencia del río Huecha. La orilla derecha se ha mantenido estable y defendida desde el núcleo de Novillas hasta la siguiente curva, en la que se ha producido una importante migración reciente. Es destacable también, como puede observarse, la presencia de un soto en 1957 desarrollado sobre el cauce de 1927, soto que ha desaparecido parcialmente en 1998. En esta última fecha se observa un notable desarrollo en madurez de la vegetación de ribera aguas abajo del núcleo de Novillas. 

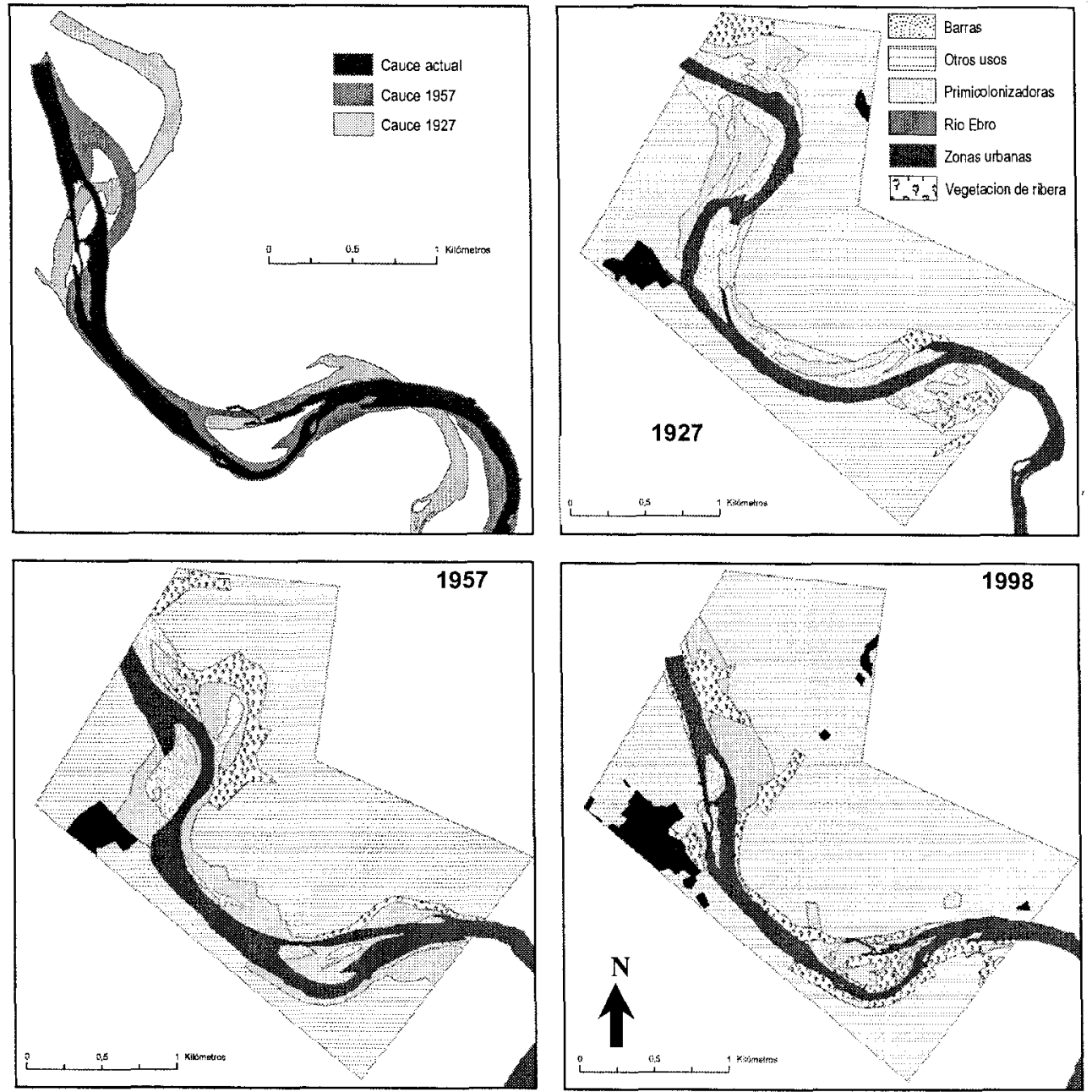

Figura 4. Mapa de movilidad del sector dinámico de Novillas y cartografía de bandas y usos en 1927,1957 y 1998

b) Sector Luceni-Cabañas: espacio que ha asistido a importantes cambios en el trazado del cauce y en las superficies ribereñas desde 1927 (figura 5). Los cambios de trazado se han registrado especialmente en el tren de meandros intermedio y entre 1927 y 1957. En el sector se ubican las localidades de Alcalá de Ebro y Cabañas en puntos de máximo riesgo (Ollero, 1996). En esta área dinámica se observa con mucha claridad la maduración de la vegetación ribereña, ocupando el terreno inicial de las primicolonizadoras, así como la colonización definitiva de las barras de grava. 

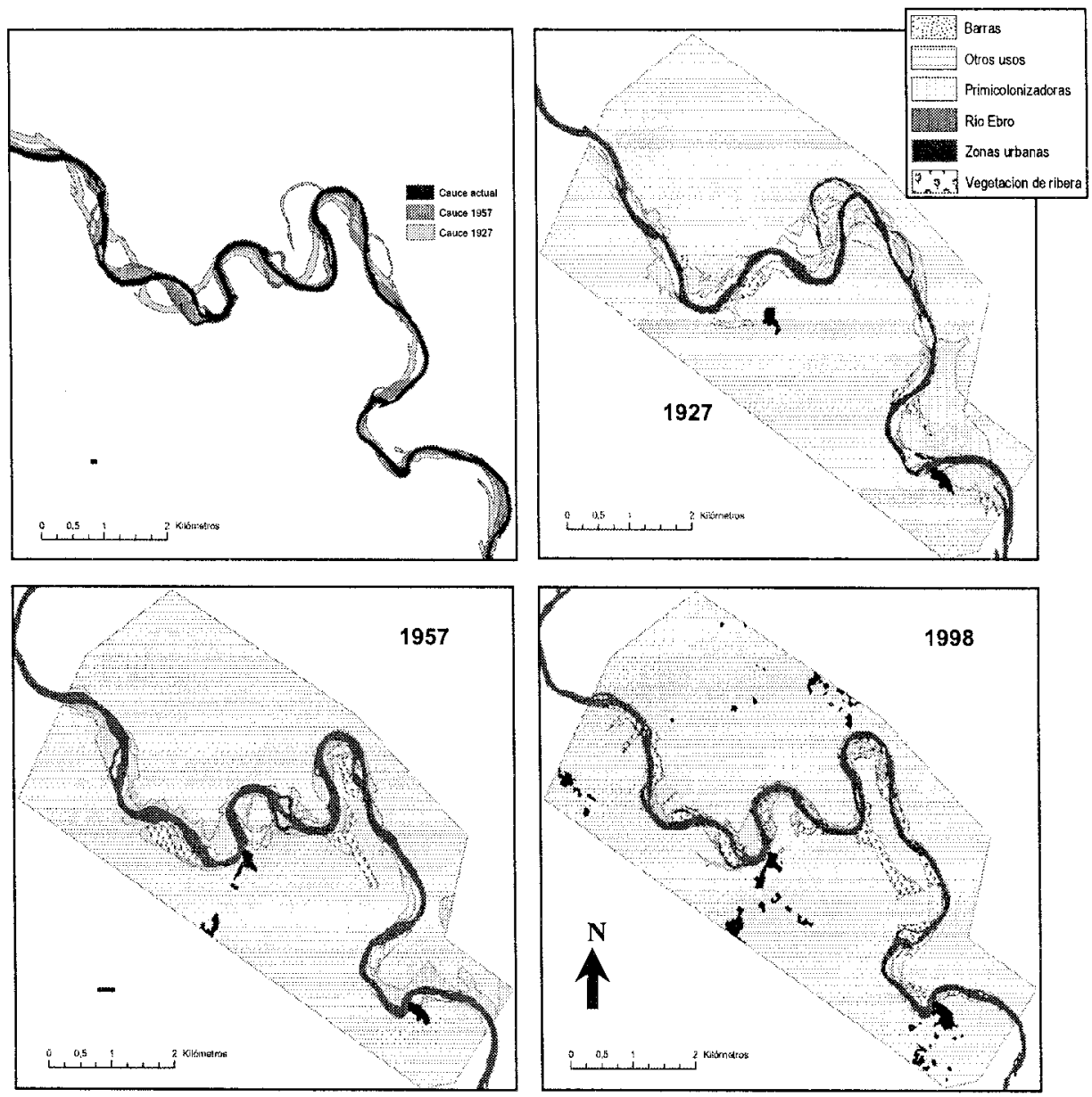

Figura 5. Mapa de movilidad del sector dinámico Luceni-Cabañas y cartografía de bandas y usos en 1927,1957 y 1998

c) Sector Sobradiel-Juslibol: este espacio también ha asistido a importantes cambios en el trazado del cauce y en las superficies ribereñas desde 1927 (figura 6). Destaca la presencia de dos cortas de cuello de meandro, aguas arriba la de Esponera, que tuvo lugar entre 1927 y 1957, y aguas abajo la del Galacho de Juslibol, registrada durante la gran crecida de enero de 1961, originando uno de los espacios fluviales más interesantes de todo el curso del Ebro. En esta área dinámica hay que destacar también el incremento progresivo e imparable de los usos humanos (cultivos y urbanización). Paralelamente, la vegetación natural ha sufrido una merma considerable. 

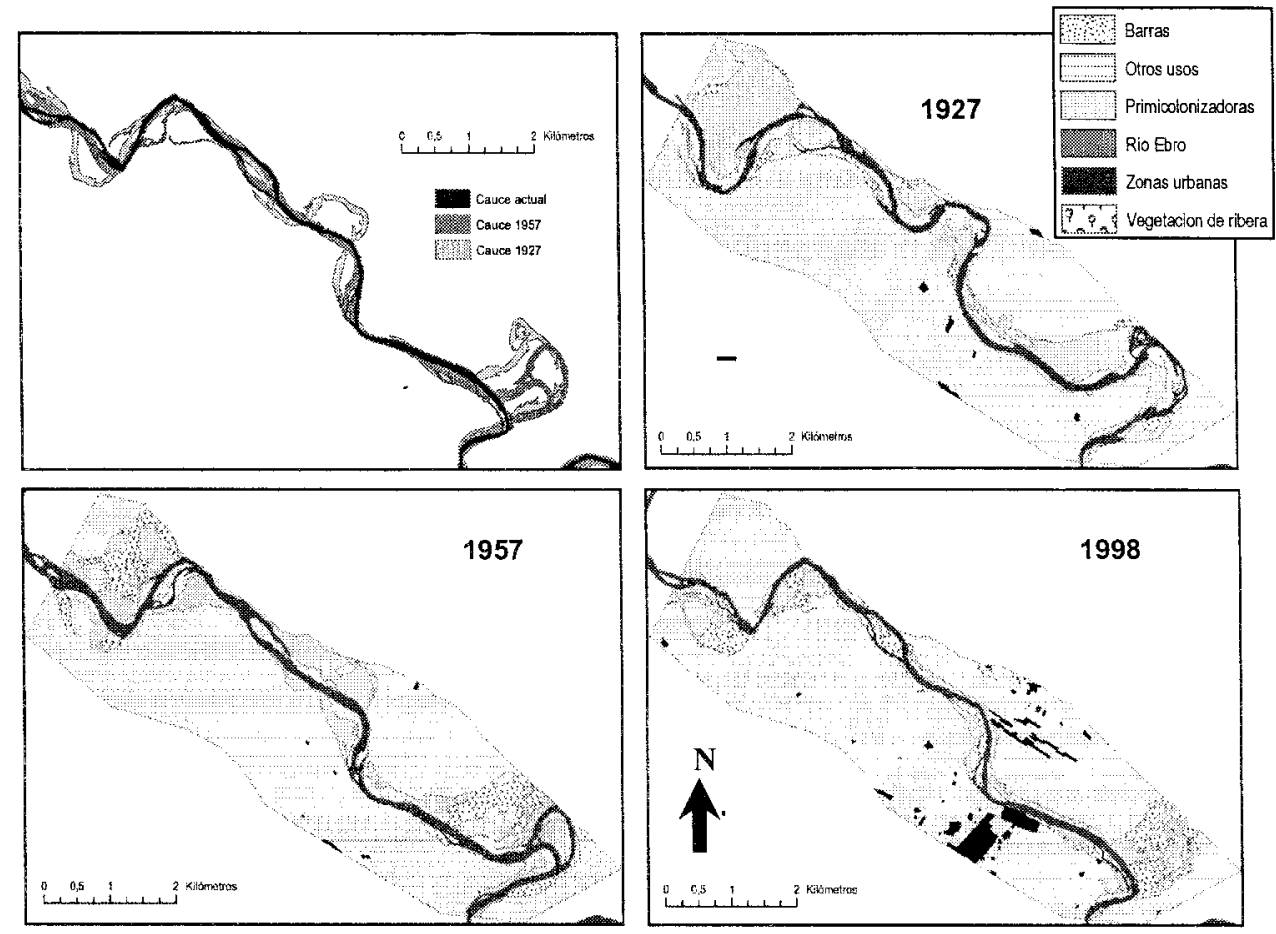

Figura 6. Mapa de movilidad del sector dinámico Sobradiel-Galacho de Juslibol y cartografía de bandas y usos en 1927. 1957 y 1998

d) Reserva Natural de los Galachos: es un espacio con importantes cambios en el trazado del cauce entre 1927 y 1957 y estabilidad posterior (figura 7), aunque conserva un destacable potencial de cambio. Los cambios de trazado más significativos tuvieron lugar en los años 30 y 40 del siglo XX, con la "rotura del Cáscaro" producida a raíz de la crecida de marzo de 1930 y la corta provocada del Galacho de Ia Alfranca (Ollero, 1995). El tramo en su mayor parte se encuentra protegido desde 1991 como Reserva Natural, pero no se han retirado las defensas construidas en la segunda mitad del siglo XX, por lo que su capacidad de movilidad no ha mejorado. En el llano de inundación destaca el mantenimiento de los sotos y el crecimiento de urbanizaciones, en muchos casos ilegales.

e) Sector Villafranca-Osera: su evolución es similar a la del sector anterior, con una dinámica muy intensa hasta 1957 y prácticamente nula con posterioridad (figura 8). Los cambios más destacables corresponden a una corta en el enclave Aladrén y 

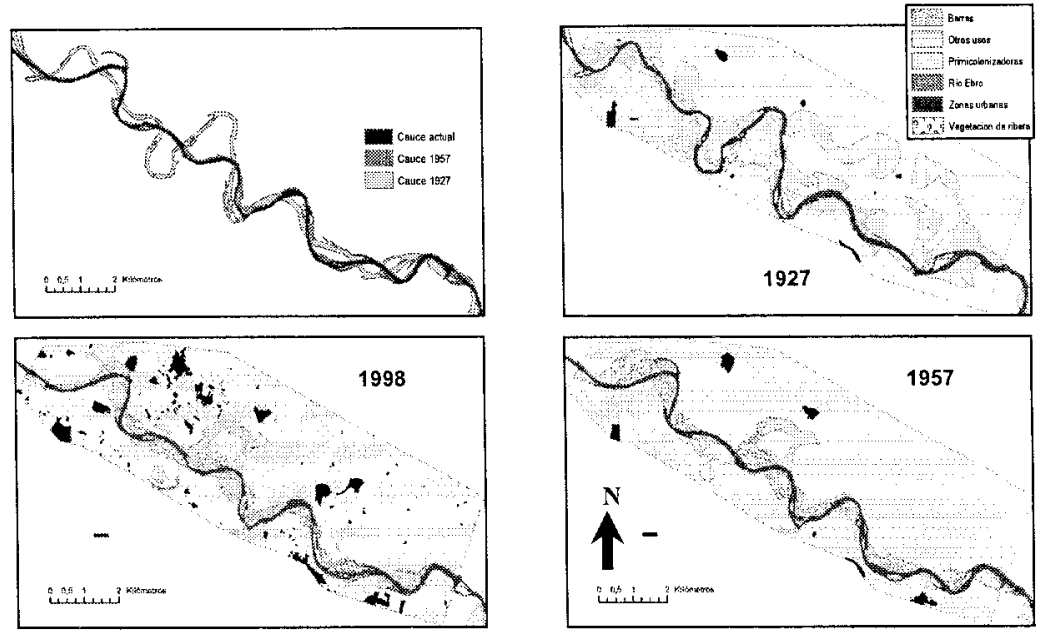

Figura 7. Mapa de movilidad del sector dinámico Reserva Natural de los Galachos y cartografía de bandas y usos en 1927, 1957 y 1998

una serie de migraciones y ampliaciones el tren se meandros siguiente. Los procesos de maduración de la vegetación de ribera y el incremento de la urbanización son rasgos evidentes.

f) Pina de Ebro: su evolución superficial es también similar a la de los dos sectores anteriores, aunque sus cambios de trazado han sido menos espectaculares (lo fueron más antes de 1927). En efecto, la dinámica ha sido compleja y variada, pero no se han producido cortas ni movimientos de muchos metros. La tendencia general ha sido hacia el incremento de la sinuosidad y a la simplificación del cauce. El tramo concluye en el meandro de Belloque, uno de los más pronunciados de todo el Ebro de meandros libres, y enormemente estable (figura 9).

\subsection{Factores de la ralentización de la dinámica}

La ralentización de la dinámica fluvial a partir de 1957 se debe fundamentalmente a causas antrópicas. Son principalmente dos factores: cambios en la cuenca y la "domesticación" directa del cauce. La entrada en servicio de numerosos embalses en la cuenca y los cambios en los usos del suelo de la misma han originado modificaciones en la morfología y en la dinámica fluvial (Frutos et al., 2004). Así, hasta 1950 el cauce del Ebro no mantenía meandros clásicos, sino que mostraba una morfología 

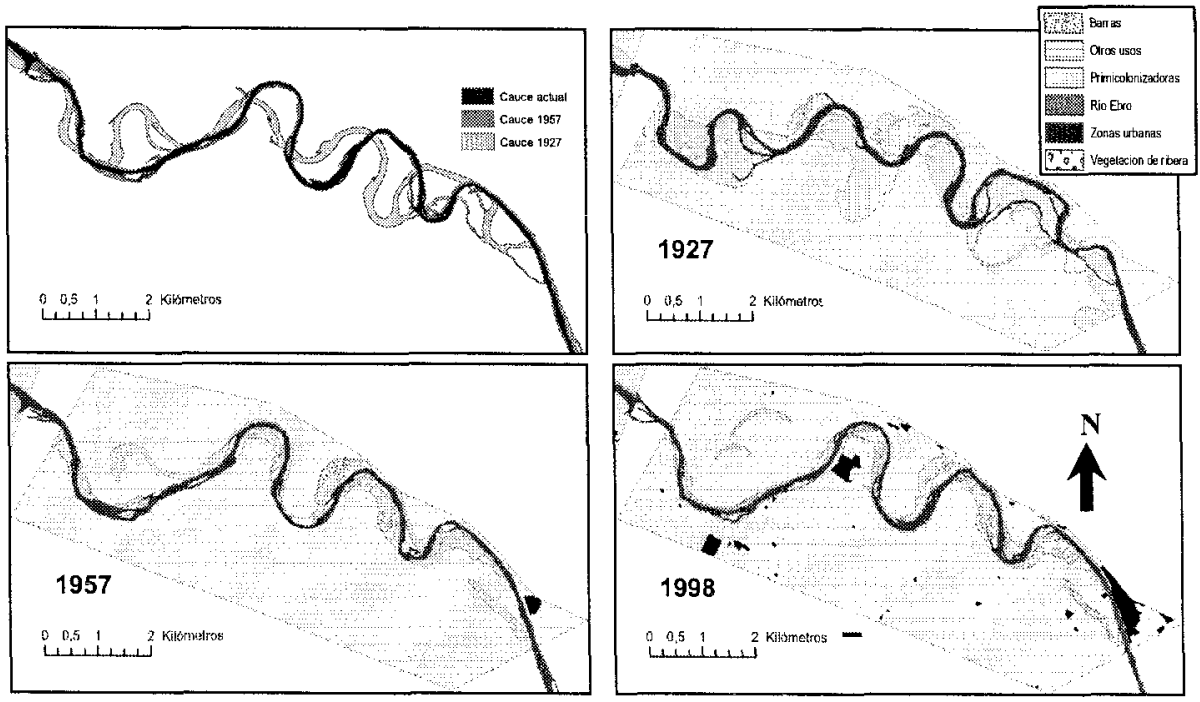

Figura 8. Mapa de movilidad del sector dinámico Villafranca-Osera y cartografía de bandas y usos en 1927, 1957 y 1998

de transición braided-meandering, correspondiendo a lo que algunos autores han venido en llamar wandering (Church, 1983). Como se observa en las fotografías aéreas de 1927 y 1946, la corriente describe meandros, algunos de gran radio, pero se divide en brazos en algunos sectores, los depósitos de sedimentos asociados al cauce son muy extensos y las variaciones de trazado parecen muy frecuentes. En la vegetación de ribera dominan las formaciones pioneras y de orla. Los escasos sotos maduros se encuentran alejados del cauce, junto a galachos. Es evidente una alta "torrencialidad" en el funcionamiento hidrológico: las crecidas son frecuentes y movilizan grandes cantidades de sedimentos, producto de una cuenca muy deforestada por la presión demográfica del medio rural, incluso en las áreas de montaña.

Pero a raíz de la crecida de 1961 se construyen numerosas defensas y se fija el cauce en buena medida, adoptando un claro trazado meandriforme (Ollero, 1992). Después de esa fecha ya no hay más cortas de meandro naturales. La consecuencia de la antropización del sistema es la invasión generalizada de las riberas para ganar terrenos de cultivo, de manera que mucha vegetación ripícola desaparece. Así, el corredor ribereño se estrecha. Paralelamente, entre 1950 y 1970 se producen cambios muy significativos en la cuenca con clara repercusión en el colector principal. Se construyen grandes embalses que reducen el número de crecidas y retienen sedimentos y, además, se abandona la economía tradicional agro-ganadera de montaña, 

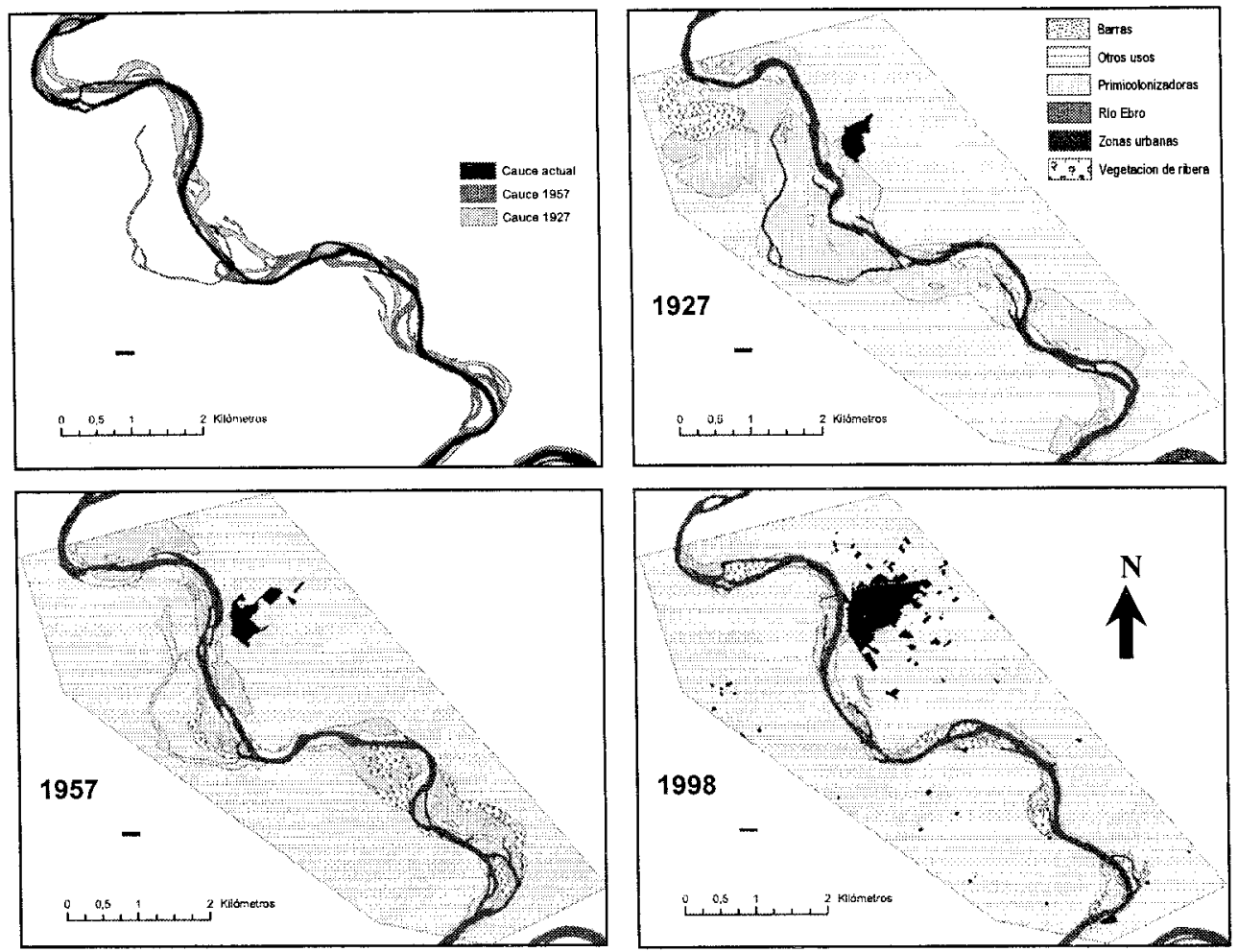

Figura 9. Mapa de movilidad del sector dinámico Pina de Ebro y cartografía de bandas y usos en 1927,1957 y 1998

ý con ello muchos pueblos y sus terrenos de cultivo, y el bosque se recupera, con lo que la escorrentía se regula y la producción de sedimentos se reduce (Frutos et al., 2004). Como consecuencia, en el Ebro aparecen los primeros síntomas de incisión, siguiendo la corriente un cauce único con muy pocas islas en las que se refugia la vegetación. Afortunadamente, algunas grandes crecidas mantienen la vitalidad de los procesos geomorfológicos y ecológicos y ralentizan el deterioro del sistema.

En los años ochenta se construye de nuevo gran número de defensas, tanto motas continuas como escolleras que protegen todas y cada una de las orillas cóncavas de los meandros. Estos ya no pueden migrar. Las únicas variaciones de trazado responden a cortas artificiales de algunas curvas (por ejemplo en Gallur). El cauce está totalmente constreñido por las defensas, a lo que hay que añadir la falta de renovación de los sedimentos y la escasez y debilidad de los procesos de crecida. En consecuencia, la vegetación coloniza todas las superficies sedimentarias y constriñe tam- 
bién a la corriente hídrica (Ollero, 2000). Los sotos ganan en madurez pero presentan también síntomas de sequía en sus sectores más alejados del río.

\subsection{Valoración de la dinámica actual y tendencias}

La dinámica natural activa de los cauces y riberas del Ebro de meandros libres en el último siglo constituye un patrimonio fluvial de gran valor geoecológico. Es un ejemplo muy relevante de dinámica en cursos meandriformes de llanura. La reducción notable de la movilidad del cauce en los últimos años implica una pérdida de parte de ese patrimonio natural y cultural, pero no de todo, ya que aún perviven elementos valiosos generados a raíz de esa dinámica activa reciente, que duró hasta los años sesenta, como por ejemplo los galachos. Curiosamente fue la gran crecida de enero de 1961 la que marcó el declive fundamental de la dinámica, ya que desde entonces se han tratado de atajar todos los posibles cambios y procesos naturales mediante obras de defensa.

En la situación actual, esta pérdida drástica de dinámica hidrogeomorfológica puede valorarse como un deterioro ambiental de consecuencias prácticamente irreversibles, a no ser que se actúe con urgencia en la restauración. En los sotos el empobrecimiento de las relaciones ecológicas y la pérdida de biodiversidad parecen ser las tendencias en los próximos años si no se actúa devolviendo terreno al río. Porque la restauración de la dinámica fluvial activa (Buijse et al., 2002) pasa fundamentalmente por el establecimiento de un Espacio de Movilidad Fluvial (Piégay et al., 1996; Malavoi et al., 1998; Ureña y Ollero, 2001), tal como se ha propuesto en un proyecto de planificación ambiental para el Ebro aragonés (Ollero et al., 2005).

Se pueda llevar a la práctica o no esa restauración global, hay también que llamar la atención y solicitar una protección especial para los siguientes elementos y enclaves de máximo valor geoecológico: las confluencias, todos los brazos ciegos por su función de biodiversidad y por ser auténticos embriones de posibles futuras dinámicas, todos los galachos (Juslibol, La Alfranca, La Cartuja, El Burgo, Osera, Pina, Bonastre) por su carácter relicto y su valor ecológico, incluyendo los ya carentes de lámina de agua pero que conservan algunas bandas de carrizal (Fornazos, Boquiñeni, Mejana del Pontón, Los Alterones), islas del cauce estabilizadas por el buen desarrollo de formaciones vegetales, puntos de contacto del cauce con escarpes, puntos y sectores de intensa dinámica reciente que son al mismo tiempo los únicos espacios del Ebro medio en los que es factible un mínimo dinamismo en el futuro, así como sectores que constituyen buenos ejemplos de las distintas tipologías del cauce.

La dinámica natural activa, representada fundamentalmente en variaciones del cauce, es en la actualidad prácticamente nula en el Ebro. Como el río está muy regu- 
lado, cabe esperar que en el futuro seguirá habiendo pocas crecidas ordinarias, que suelen ser laminadas con facilidad, y algunas extraordinarias que no podrán ser laminadas por los embalses. Ello quiere decir que habrá dinámica, incluso con defensas, porque éstas también fallan, pero esa dinámica podrá consolidarse si no se actúa en contra de ella, o bien atajarse si cualquier inicio de cambio es rápidamente controlado. Hay algunos puntos donde pueden preverse procesos erosivos y ligeros cambios de trazado en los próximos años: ciertas curvas irregulares del cauce con vértices pronunciados, puntos de debilidad de la margen con riesgo de corta, meandros poco desarrollados, defensas mal ubicadas o que generan problemas de erosión en la margen opuesta, etc.

La colmatación de brazos secundarios, ciegos y galachos constituye otro proceso actualmente activo. Son espacios de interesante evolución en los que pervive la dinámica entendida como capacidad de cambio, y se encuentran asociados en la mayor parte de los casos a sotos de alto valor. La tendencia a la colmatación de todos ellos está siendo más lenta que en funcionamiento natural, por el predominio de aguas limpias. La escasez de sedimentos circulantes y sobre todo de crecidas está ralentizando el proceso de colmatación de los actuales galachos, que están perviviendo, en general, durante más años que los antiguos cauces abandonados que tapizan el llano de inundación. Esto es positivo para que sigan cumpliendo sus funciones ecológicas y educativas, pero es un síntoma más de la deceleración de la dinámica natural.

\section{Conclusiones}

La dinámica fluvial en el Ebro medio ha sido muy activa, constituyendo en sí misma un enorme valor ecológico y ambiental que hace de este curso fluvial un patrimonio natural de gran valor en el contexto de la cuenca y peninsular. Pero el cauce y las riberas del Ebro han ido siendo progresivamente constreñidos, ocupados por las actividades humanas, restringiéndose con ello poco a poco su dinámica natural, su capacidad de cambio, madurando en consecuencia la vegetación, a veces excesivamente. En las últimas décadas se ha asistido también a un incremento de los espacios urbanizados dentro del llano de inundación, aunque la actividad agraria sigue siendo predominante.

Para el análisis cuantitativo de estos cambios ha sido muy útil la integración de las fotografías aéreas de 1927, 1957 y 1998 en un Sistema de Información Geográfica. Desde 1927 se han observado cambios de trazado en 83 enclaves del área de estudio. Los cambios más frecuentes corresponden a ampliación de sinuosidad (38 casos), seguidos de la migración del meandro aguas abajo (32 casos), combinación de ampliación y migración (21 casos), acortamientos por canal de crecida (17 casos) y 
cortas de cuello ( 7 casos). La superficie movilizada fue de casi 2.000 hectáreas en 30 años (1927-57), mientras en el último medio siglo ha sido de solo unas 400 hectáreas.

En el análisis cuantitativo de superficies de la llanura de inundación, destaca el progresivo y considerable descenso de la superficie ocupada por el cauce inundado y las barras de grava sin colonización vegetal. La vegetación de ribera ha descendido en superficie, muy destacablemente en primicolonizadoras. Entre 1957 y 1998 se ha reducido drásticamente la anchura de la vegetación de ribera y del corredor ribereño, cuya superficie actual no llega al 58\% de la que ocupaba en 1927. La masiva construcción de defensas ha estabilizado el trazado del cauce menor y ha consolidado la invasión humana del espacio fluvial.

La dinámica fluvial del Ebro de meandros libres en Aragón ha sido muy reducida, casi eliminada, y solo podrá recuperarse con una solución activa, como la del Espacio de Movilidad Fluvial, que conlleve la eliminación o el alejamiento de las actuales defensas. Si no se actúa así la pérdida de patrimonio va a ser irreparable. La restauración de una dinámica natural activa debería ser clave para la correcta gestión territorial del Ebro, para la mejora de sus ecosistemas y para la minimización de los riesgos.

\section{Referencias}

Acín. V. (2004) Cambios en la dinámica fluvial de los rios Gállego (tramo BiescasSabiñánigo) y Aurín en los últimos 50 años. Proyecto Fin de Carrera. Dpto. de Geografía y Ordenación del Territorio, Universidad de Zaragoza.

Apan, A.A.; Raine, S.R. y Paterson, M.S. (2002) Mapping and analysis of changes in the riparian landscape structure of the Lockyer Valley catchment, Queensland, Australia. Landscape and Urban Planning, 59, 43-57.

Batalla, R.J. (2003) Sediment deficit in rivers caused by dams and instream gravel mining. A review with examples from NE Spain. Cuaternario y Geomorfologia, 17(3-4): 79-91.

Batalla, R.J.; Gómez, C.M: y Kondolf, G.M. (2004) Reservoir-induced hydrological changes in the Ebro river basin (NE
Spain). Journal of Hydrology, 290, $117-$ 136.

Beguería, S.; López Moreno, J.I.; Seeger, M. y García Ruiz, J.M. (2003) Assessing the effect of climate oscillations and land-use changes on streamflow in the Central Spanish Pyrenees. Ambio, 32, 4, 283-286.

Brandt, S.A. (2000) Classification of geomorphological effects downstream of dams. Catena, 40, 375-401.

Bravard, J.P. (1991) La dynamique fluviale à l'épreuve des changements environnementaux: quels enseignements applicables à l'aménagement des rivières? $L a$ Houllle Blanche, 7/8, 515-521.

Bray, D.I. y Kellerhals, R. (1979) Some canadian examples of the response of rivers to man-made changes. In Rhoddes, D.D. y Williams, G.P. (Eds.): Adjustments of the fluvial system, 351-372. 
Brice, J.C. (1964) Channel patterns and terraces of the Loup River in Nebraska. United States Geological Survey, Prof. Paper 422D, $41 \mathrm{p}$.

Brice, J.C. (1981) Stability of relocated stream cbannels. Technical Report RD-80/158, Federal Highways Administration, 177 p., Washington, DC.

Brookes, A. (1987) The distribution and management of channelized streams in Denmark. Regulated Rivers: Research and Management, 1, 3-16.

Buijse, A.D.; Coops, H.; Staras, M.; Jans, L.H.; Geest, G.J. van; Grift, R.E.; Ibelings, B.W.; Oosterberg, W. y Roozen, F.C.J.M. (2002) Restoration strategies for river floodplains along large lowland rivers in Europe. Fresbwater Biology, 47, 889-907.

Chorley, R.J. y Kennedy, B.A. (1971) Physical Geograpby: a systems approach. London, Prentice Hall.

Church, M. (1983) Patterns of instability in a wandering gravel bed channel. In Collinson, J.D. y Lewin, J. (eds.): Modern and ancient fluvial systems, 169-180, London, Blackwell.

Conesa, C. (1999) Cambio ambiental y equilibrio dinámico de los cauces. Papeles de Geografia, 30, 31-46.

Décamps, H.; Fortuné, M. y Gazelle, F. (1989) Historical changes of the Garonne river, Southern France. In Petts, G.E.; Möller, H. y Roux, A.L. (Eds.): Historical change of large alluvial rivers: Western Europe, 249267, Chichester, Wiley.

Downs, P.W. (1992) Spatial variations in river channel adjustments: implications for channel management in soutb-east England. Unpublished PhD thesis, 340 p., University of Southampton.

Frutos, L.M.; Ollero, A. y Sánchez, M. (2004) Caracterización del Ebro y su cuenca $y$ variaciones en su comportamiento hidrológico. En Gil Olcina, A. (Coord.):
Alteración de los regimenes fluviales peninsulares, 233-280, Fundación Cajamurcia.

García Martínez, B. y Baena, R. (2001) Los embalses de regulación como inductores de cambios hidrológicos y morfológicos en los ríos de Andalucía occidental. Actas del XVII Congreso de Geógrafos Españoles, 163-165, Oviedo, Asociación de Geógrafos Españoles.

García Ruiz, J.M.; Beguería, S.; López, J.I.; Lorente, A. y Seeger, M. (2001) Los recursos bidricos superficiales del Pirineo Aragonés y su evolución reciente. Logroño, Geoforma.

Gergel, S.E.; Dixon, M.D. y Turner, M.G. (2002) Consequences of human-altered floods: levees, floods, and floodplain forests along the Wisconsin river. Ecological Applications, 12(6), 1755-1770.

Goswami, U.; Sarma, J.N. y Patgiri, A.D. (1999) River channel changes of the Subansiri in Assam, India. Geomonpbo$\operatorname{logy}, 30,227-244$.

Granado, D. (2004) Dinámica fluvial y vegetación de ribera del río Aragón en el tramo Jaca - Puente la Reina de Jaca. Proyecto Fin de Carrera. Dpto. de Geografía y Ordenación del Territorio, Universidad de Zaragoza.

Hooke, J.M. (1997) Styles of channel change. In Thorne, C.R.; Hey, R.D. y Newson, M.D. (Eds.): Applied fluvial geomorpbology for river engineering and management, 237-268, Chichester, wiley.

Keesstra, S.D.; van Huissteden, J.; Vandenberghe, J.; Van Dam, O.; de Gier, J. y Pleizier, I.D. (2005) Evolution of the morphology of the river Dragonja (SW Slovenia) due to land-use changes. Geomorphology, 69, 191-207.

Lajczak, A. (1995) The impact of river regulation, 1850-1990, on the channel and floodplain of the upper Vistula river, sou- 
thern Poland. In Hickin, E.J. (Ed.): River Geomorpbology, 209-233, New York, wiley.

Liébault, F. y Piégay, H. (2002) Causes of $20^{\text {th }}$ century channel narrowing in mountain and piedmont rivers of Southeastern France. Earth Surface Processes and Landforms, 27, 425-444.

Macklin, M.G. y Lewin, J. (1997) Channel, floodplain and drainage basin response to environmental change. In Thorne, C.R.; Hey, R.D. y Newson, M.D. (1997): Applied fluvial geomorphology for river engineering and management, 15-45, Chichester, Wiley.

Malavoi, J.R.; Bravard, J.P.; Piégay, H.; Héroin, E. y Ramez, P. (1998) Determination de l'espace de liberté des cours d'eau. Lyon, SDAGE Rhône-Méditerranée-Corse.

Marston, R.A.; Girel, J.; Pautou, G.; Piégay, H.; Bravard, J.P. y Arneson, C. (1995) Channel metamorphosis, floodplain disturbance, and vegetation development : Ain River, France. Geomorpbology, 13, 121-131.

Ollero, A. (1991) Estudio ecogeográfico de los meandros del Ebro en el sector Rincón de Soto-Novillas. Madrid, Ministerio de Obras Públicas y Transportes.

Ollero, A. (1992) Los meandros libres del Ebro medio (Logroño-La Zaida): geomorfología fluvial, ecogeografia y riesgos. Tesis doctoral. Departamento de Geografía y Ordenación del Territorio, Universidad de Zaragoza, 1.138 p. + cartografía.

Ollero, A. (1995) Dinámica reciente del cauce del Ebro en la Reserva Natural de los Galachos (Zaragoza). Cuatemario y Geomorfologia, 9(3-4), 85-93.

Ollero, A. (1996) Dinámica de meandros y riesgos hidrogeomorfológicos en Alcalá de Ebro y Cabañas de Ebro (Zaragoza). $I V$ Reunión Nacional de Geomorfología,
Cadernos do Laboratorio Xeolóxico de Laxe, 21, 431-443.

Ollero, A. (2000) Las riberas del Ebro medio: diagnosis y ordenación de un paisaje fluvial amenazado. II Congreso Ibérico sobre Planificación y Gestión de Aguas, 139. 150, Oporto.

Ollero, A. (dir., 2005) Estudio bidrológico, geomorfológico, bidráulico y ecológico del bajo Gállego en el T.M. de Zaragoza para su gestión como espacio fluvial. Convenio de investigación Universidad de Zaragoza-Ayuntamiento de Zaragoza (inédito).

Ollero, A. y Pellicer, F. (1989) Las fotografias aéreas de la C.S.H.E. (1927): un documento básico para el estudio de las riberas del Ebro. Actas II Reunión del Cuatemario Ibérico, t. II, 897-904, AEQUA y SEG, Madrid.

Ollero, A. y Pellicer, F. (1991) Middle Ebro river channel and floodplain: geomorphology, recent changes, risks and management on a fluvial system of free meanders. In Sala, M.; Rubio, J.M. y García Ruiz, J.M. (Eds.): Soil erosion studies in Spain, 203-210, Logroño, Geoforma.

Ollero, A.; Sánchez Fabre, M. y Del Valle, J. (2004) Problemática actual del corredor ribereño del Ebro aragonés en su curso de meandros libres. En Peña, J.L.; Longares, L.A. y Sánchez Fabre, M. (Eds.): Geografía Física de Aragón. Aspectos generales y temáticos, 253-263. Universidad de Zaragoza.

Ollero, A.; Ballarin, D. y Mora, D. (2005) El fundamento ambiental del Plan: una dinámica fluvial activa. Estudio monográfico 2 del Plan Medioambiental del Ebro y tramo bajo del Cinca, 253 p. + anexos, Departamento de Medio Ambiente del Gobierno de Aragón (inédito). 
Piégay, H.; Barge, O. y Landon, N. (1996) Streamway concept applied to river mobility / human use conflict management. First International Conference on New/Emerging Concepts for Rivers. Proceedings Rivertech 96, 681-688, I.W.R.A.

Rinaldi, M. (2003) Recent channel adjustments in alluvial rivers of Tuscany, central Italy. Earth Surface Processes and Landforms, 28, 587-608.

Roux, A.L.; Bravard, J.P.; Amoros, C. y Pautou, G. (1989) Ecological changes of the french upper Rhône river since 1750 . In Petts, G.E.; Möller, H. y Roux, A.L. (Eds.): Historical changes of large alluvial rivers: western Europe, 323-350.

Rumsby, B.T. y Macklin, M.G. (1994) Channel and floodplain response to recent abrupt climate change: the Tyne basin, northern England. Earth Surface Processes and Landforms, 19, 499-515.

Rutherfurd, I. (2000) Some human impacts on Australiam stream channel morphology. In Brizga, S. y Finlayson, B. (Eds.): River management: the Australasian experience, 11-49, Chichester, Wiley.

Schumm, S.A. (1968) River adjustment to altered bydrological regime (Marmubidgee river and palaeochannels, Australia). Professional paper of the U.S. Geological Survey, 598.
Surian, N. (1999) Channel changes due to river regulation: the case of the Piave river, Italy. Earth Surface Processes and Landforms, 24, 1135-1151.

Surian, N. y Rinaldi, M. (2003) Morphological response to river engineering and management in alluvial channels in Italy. Geomorphology, 50, 307-326.

Thorne, C.R. (1998) Stream reconnaissance bandbook: geomorpbological investigation and analysis of river channels. Chichester, wiley

Ureña, J.M. y Ollero, A. (2001) Fluvial landscapes, catchment administration and land-use planning: experience based on two rivers in Spain. Landscape Research, 26(3), 225-243.

Uribelarrea, D.; Pérez-González, A. y Benito, G. (2003) Channel changes in the Jarama and Tagus rivers (central Spain) over the past 500 years. Quatemary Science Reviews, 22, 2209-2221.

Werritty, A. (1997) Short-term changes in channel stability. In Thorne, C.R.; Hey, R.D. y Newson, M.D. (Eds.): Applied fluvial geomorpbology for river engineering and management, 47-65, Chichester, wiley.

Winterbottom, S.J. (2000) Medium and shortterm channel planform changes on the rivers Tay and Tummel, Scotland. Geomorpbology, 34, 195-208. 